\title{
DELIVERY AFTER PREVIOUS CAESAREAN SECTION
}

\author{
Lieutenant-Colonel L. W. PADGETT, M.B., B.S., M.R.C.O.G., R.A.M.C. \\ Louise Margaret Maternity Hospital, Aldershot
}

SUMMARY: A personal series of 144 patients previously delivered by Caesarean Section is presented. Successful vaginal delivery was attained in 72.3 per cent of the total and 90.5 per cent of the 115 who were allowed to labour. There was no maternal mortality or significant maternal morbidity and no attributable perinatal death.

\section{Introduction}

The management of the delivery of a patient who has been previously delivered by Caesarean section poses problems the solution of which remains controversial. British and Commonwealth practice on the whole is to anticipate vaginal delivery if at all possible. The Second report of the British Perinatal Mortality Survey (1969) gives an overall incidence of vaginal delivery after previous Caesarean section of almost 55 per cent and this is similar to that reported by McGarry (1969) who quotes 58.3 per cent. In a recent paper Case et al (1971) and the team in Liverpool sound a note of caution and report that between 1951 and 1967 at the Mill Road Maternity Hospital, Liverpool the percentage of patients delivered vaginally dropped from 70 to 35 and the proportion of elective repeat sections rose from 20 to almost 50 per cent.

This paper reports the results in the management at the Louise Margaret Maternity Hospital, Aldershot of 144 patients previously delivered by Caesarean section. These patients make up 3.2 per cent of the total deliveries in 1969, 1970 and 1971 (4483) and of this number 104 (72.3 per cent) were delivered vaginally with no maternal mortality, no rupture of the scar and no attributable perinatal deaths.

Although the numbers are small it is felt that the results are significant in that they comprise a personal series in which the value of close supervision is illustrated.

\section{Antenatal assessment}

The policy at the Louise Margaret Maternity Hospital was to refer all patients previously delivered by Caesarean section for Consultant assessment as soon as possible after booking. At this stage the collation of information from previous pregnancies was initiated with particular emphasis on the indication or indications for the previous Caesarean section, the length of labour if any, and the station of the presenting part and dilation of the os at the time of operation. Any pelvimetry report available was studied and here it may be pointed out that a full postnatal pelvimetry carried out after the previous Caesarean section was found to be of value in cases in which an element of previously unsuspected disproportion existed. These cases were nearly always associated with a deflexed occiput posterior position of the head. Patients previously operated on for disproportion, particularly when associated with a deflexed head, were not excluded from the assessment for vaginal delivery.

An effort: was made to advise the patient, at least by the mid trimester, of the probable management of her case. Those selected for elective repeat Caesarean section (Table I) formed a small and easily advised group. Patients considered to have a good chance of vaginal delivery, were told this and to improve their confidence were seen 
throughout their pregnancy by the Consultant as far as this was possible. Women with one child only quite naturally required the most support, and in particular those of the large group whose labour had been prolonged. Their chance of vaginal delivery was explained and they were promised a labour of limited duration with early Caesarean section if things were not going well. It was found that this policy of close antenatal supervision paid greatly in patient confidence and co-operation.

Lateral erect X-ray pelvimetry was carried out as indicated on clinical grounds. In patients who had been previously delivered abdominally for disproportion or in whom the head was not engaged at the time of section, pelvimetry was performed unless an earlier report was available.

Apart from very gentle effort, external version for breech presentation was not attempted. However, this presentation was not regarded as an absolute contra-indication to vaginal delivery and the two cases in the series were assessed as for any other breech presentation.

In the only case of twins labour began prematurely at 33 weeks gestation with the rapid vaginal delivery of babies weighing $2010 \mathrm{~g}$. each.

Table I

29 Cases of elective repeat caesarean section

\begin{tabular}{l|c|l|c}
\hline & Number & & Number \\
\hline Two previous lower segment operations & 10 & Bad obstetric history & 4 \\
Previous classical operation & 4 & Placenta praevia & 1 \\
Suspect scar & 3 & Transverse lie (Bicornute uterus) & 1 \\
Disproportion & 5 & Eclampsia & 1 \\
\hline
\end{tabular}

\section{Elective repeat Caesarean sections}

Elective repeat operations were carried out on 29 patients (20.1 per cent). Although there seems to be no proof that more than one previous lower segment operation increases the risk of uterine rupture (Riva and Teich 1961) one would agree with McGarry (1969) that it is unreasonable to subject these patients to a "trial of scar" in most cases. The four cases of previous Classical Caesarean section should excite no comment and the three cases of "suspect scar" included two cases in which an inverted-T-shaped incision had been used, and one case in which infection, paralytic ileus and burst abdomen had occurred as complications of the previous operation. Other less severe cases of previous "wound infection" were allowed to labour. The four cases in which an elective repeat operation was carried out for a bad obstetric history comprised three women aged over 30 years who had a previous perinatal death, and one aged 38 with a three year history of involuntary infertility.

Patients who had the usual transverse lower segment scar were admitted a few days before term and repeat section carried out at term. Those who had had Classical operations or a vertical lower uterine scar were admitted at 36 weeks for operation at 38 weeks.

In this group of patients one found no scar ruptures nor significant maternal morbidity. There was one unexpectedly immature baby weight $2160 \mathrm{~g}$ which survived. 
There was one perinatal death when the $2720 \mathrm{~g}$ infant of a West African patient having her third section died from atelectasis.

\section{Management in Labour}

Induction of labour was approached with caution particularly in those patients previously sectioned for failed induction. This was to try and avoid adding a possibly unnecessary complication to the case. Surgical induction was required in 27 cases (18.7 per cent) of which four required a repeat operation for failed induction (Table II). Of 14 patients previously delivered abdominally for failed induction and allowed to labour, none required induction in the next pregnancy and all delivered vaginally.

Oxytocin was administered as indicated in either inco-ordinate labour or the day after surgical rupture of the membranes if labour was not established. It seems illogical not to use this drug to stimulate labour provided that supervision is close. Intravenous Syntocinon four units in one litre of 5 per cent Dextrose in water was administered at a slowly rising rate of infusion and this stimulation was required in 28 cases. Of this group eight came to repeat Caesarean section, four for inco-ordinate labour and four for failed induction (Table II). If no satisfactory response to Syntocinon occurred on the first day of administration no further attempt was made.

Every case in labour was treated as a "trial of labour" in that assessment was carried out by the doctors and the patient was assessed at least once by the Consultant or Senior Registrar. No labour was allowed to go over 24 hours and most cases came to delivery or a decision for Caesarean section within 15 hours. Obstetric forceps and the Vacuum extractor were used as indicated. Although like McGarry (1969) one would not consider the presence of a scar per se to indicate assistance in the second stage the combined forceps and Ventouse rate was 31 per cent (Table III), some three times higher than the overall rate for the hospital. Analgesia used was the routine Pethidine hydrochloride and Promazine in the first stage with pudendal block or vulval infiltration for assisted deliveries.

Syntometrine was given at the delivery of the anterior shoulder and the placanta delivered by controlled cord traction. Only two cases required the potentially dangerous procedure of manual removal of the placenta. Internal palpation of the lower segment of the uterus was carried out immediately after delivery in all cases.

Table II

11 Cases of non-elective repeat caesarean section

\begin{tabular}{l|c|l|c}
\hline & Number & & Number \\
\hline $\begin{array}{l}\text { Failed induction } \\
\text { Inco-ordinate uterine action }\end{array}$ & 4 & Persistent occiput-posterior & 3 \\
\hline
\end{tabular}

\section{Non-elective repeat Caesarean sections}

One hundred and fifteen patients were selected for a trial of vaginal delivery and of these 11 (9.5 per cent) required repeat Caesarean section (Table II). Repeat operations in all these cases were carried out at a much earlier stage than would be usual in 
non-scarred uterus. Induction was regarded as failed after one day on a Syntocinon drip and labour as prolonged (due to inco-ordinate uterine action or a deflexed occiput posterior position) after a maximum of 12 hours. Only two of this group of cases had progressed beyond three finger dilation in a previous labour and one of these required her repeat Caesarean section when the premature induction failed (at 36 weeks) of a baby affected by Rhesus haemolytic disease.

There were no perinatal deaths in this group.

Table III

105 Cases of vaginal delivery

\begin{tabular}{|c|c|c|}
\hline & Number & Per cent \\
\hline Spontaneous vertex delivery & 70 & 66.7 \\
\hline $\begin{array}{l}\text { Ventouse extraction } \\
\text { Indications:-Delay 1st stage } \\
\text { Delay 2nd stage-Occiput-anterior } \\
\text { Occiput-posterior }\end{array}$ & $\begin{array}{r}21 \\
5 \\
10 \\
6\end{array}$ & \\
\hline $\begin{array}{l}\text { Forceps } \\
\quad \text { Indications:-Delay 2nd stage- Occiput-anterior } \\
\text { Occiput-posterior }\end{array}$ & $\begin{array}{r}12 \\
9 \\
3\end{array}$ & \\
\hline Assisted breech delivery & 2 & \\
\hline
\end{tabular}

\section{Vaginal delivery}

One hundred and four patients delivered vaginally (Table III). These represent 72.3 per cent of all cases in the series or 90.5 per cent of those cases allowed a trial of vaginal delivery. The 70 spontaneous vertex deliveries includes one set of twins. The high rate of assistance by Ventouse or forceps has been commented upon already. Interference in the second stage with the occiput anterior (19 times in a total of 34) was related to the obstetricians anxiety. The use of Kiellands forceps on three occasions to rotate and deliver the head deserves comment. These procedures were carried out under general anaesthesia in the operating theatre and in all the presenting part was at the mid-cavity or lower. Nevertheless the risk of damage to the lower segment scar must have been high and the use of the Ventouse in such circumstances should be preferred.

Two perinatal deaths occurred in this group of patients.

One lady previously delivered by Caesarean section for inco-ordinate labour went into spontaneous labour at 32 weeks and delivered an infant of $1590 \mathrm{~g}$ which died from the respiratory distress syndrome. In the other case the patient had had two previous Caesarean sections and was due for elective repeat operation. She had an ante-partum haemorrhage at 28 weeks, established into labour and rapidly delivered an infant of $1160 \mathrm{~g}$ which died after 30 minutes. Neither of these deaths could be attributed to the decision to allow vaginal delivery.

\section{Secundigravida}

Amongst the 144 patients were 88 who had only one previous pregnancy and which had ended in Caesarean section, and 71 of these were allowed to attempt vaginal 
Table IV

71 Patients of Parity 1

\begin{tabular}{l|c|c}
\hline & Number & Per cent \\
\hline $\begin{array}{l}\text { Non-elective repeat caesarean section } \\
\text { Vaginal delivery }\end{array}$ & 9 & 12.6 \\
\hline
\end{tabular}

Indications for previous caesarean section

Prolonged labour (Occiput posterior/ inco-ordinate labour

"Disproportion"

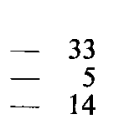

Foetal distress

Breech

Failed induction

Ante-partum haemorrhage

Eclampsia

delivery (Table IV). This group represents the biggest problem in management because of the "unknown quantity" similar to that posed by a primigravida. Certainly patients who had previous vaginal deliveries as well as Caesarean section presented few problems, in that of 46 allowed a trial of vaginal delivery 44 (95.6 per cent) succeeded, and one of the failures was complicated by Rhesus haemolytic disease as mentioned earlier.

Table IV indicates the outcome in the 71 secundigravida expected to deliver vaginally and the indications for the previous Caesarean section. The proportion of the various indications for Caesarean section seems to be as expected. Of particular interest is the outcome of the trial of vaginal delivery in 38 patients in whom the previous section had been carried out for mechanical, and therefore potentially recurrent, factors (prolonged labour due to inco-ordinate uterine action associated with the occiputposterior position and disproportion) (Table V).

McGarry (1969) gives a relatively poor prognosis for subsequent vaginal delivery (60 per cent as opposed to an 80 per cent chance for cases previously delivered abdominally for non-mechanical factors (ante-partum haemorrhage, foetal distress). The figures from the Louise Margaret Maternity Hospital in fact show that there is a 9 in 10 chance of safe vaginal delivery in the type of case under consideration and this hardly differs from the overall figures. A final observation is that 13 out of these 34 babies were bigger than the bady delivered at the previous Caesarean section. This points to the importance of uterine action and soft tissue resistance in determining the successful outcome of a first labour.

Table V

38 Cases of previously prolonged labour/disproportion

\begin{tabular}{l|r|r}
\hline & Number & Per cent \\
\hline $\begin{array}{l}\text { Non-elective repeat caesarean section } \\
\text { Reason for repeat caesarean section } \\
\text { Recurrent inco-ordinate labour } \\
\text { Delay due to recurrent occiput-posterior } \\
\text { Failed induction }\end{array}$ & 4 & 10.5 \\
\hline $\begin{array}{l}\text { Vaginal delivery } \\
\text { Spontaneous vertex delivery } \\
\text { Forceps/ventouse }\end{array}$ & 2 & 1 \\
\hline
\end{tabular}




\section{Discussion}

The problem is to balance the risks to Mother and foetus in elective repeat Caesarean section against that of vaginal delivery plus the ever present chance of rupture of the scar at the site of the previous operation. The Report on Confidential Enquiries into Maternal deaths in England and Wales 1964 to 1966 quotes six deaths due to anaesthetic complications at the time of elective Caesarean section and four deaths due to sepsis following this procedure. These are in addition to deaths from pulmonary embolus or haemorrhage which may have occurred but were not listed under a separate heading. On the other hand amongst 30 women who died following rupture of the uterus in only three cases was the rupture associated with a previous Caesarean section scar. One of these was a Classical scar and the two lower segment scars ruptured in association with manipulation of the uterus to remove a retained placenta.

Foetal risk related to mode of delivery has been assessed in the Second Report of the 1958 British Perinatal Mortality Survey (1969). Expressing the overall perinatal mortality rate as a ratio of 100 , the relative risk in babies born at elective repeat Caesarean section was 142 , and 190 in those born by spontaneous vaginal delivery after previous section. The relative risk after assisted delivery in similar cases was 199. After excluding deaths at elective repeat section associated with other complications in addition to the uterine scar (for example toxaemia, A.P.H.) there were 17 deaths in which the major factor was unsuspected immaturity (and Hyaline membrane disease).

It would appear therefore that delivery of the baby by elective repeat Caesarean section can be significantly safer for the baby although avoidable deaths due to unsuspected immaturity will occur. Vaginal delivery, however, will be safer for the mother and this is confirmed by Case et al (1971) who assess the increased risk of elective Caesarean section as between 3 and 7 times.

If it is possible to reduce the perinatal risk at vaginal delivery following a previous Caesarean section to that of uncomplicated vaginal delivery or even to that following elective repeat Caesarean section then it seems logical to try and attain vaginal delivery. Some maternal deaths will be avoided, and it is unlikely that many will be caused by rupture of a lower segment scar. Foetal loss following rupture of the scar, which is very high is likely to be outweighed by the perinatal loss following elective repeat operations due to unexpected immaturity.

Careful antenatal selection to weed out the higher risk cases and close intrapartum supervision with quick resort to repeat Caesarean section if necessary has been shown to produce acceptable results to mother and baby. It remains important to continue to give each case individual attention to avoid relaxation of vigilance or a "deliver vaginally at all costs" attitude. As Case et al (1971) points out there is no way satisfactory to assess a uterine scar either before or after labour, but one would not agree with their comment that lower segment scars commonly rupture.

Management of cases selected for a trial of vaginal delivery includes induction of labour if indicated on the usual grounds, the use of oxytocic drugs and of means to assist delivery in the second stage. Induction of labour on the grounds of previous Caesarean section alone however seems to be adding an unnecessary complication. We would eschew external version, intra-uterine manipulation and would suggest that 
manual removal of a retained placenta be carried out by experienced staff. Rotation and delivery with Kielland's forceps must be regarded as particularly dangerous.

A previous history of disproportion particularly when associated with deflexion of the head by no means implies exclusion of future vaginal delivery and a successful vaginal outcome can be expected in 9 cases out of 10 . A previous labour, particularly if dilation of the os reached $3 \mathrm{~F}$ improves the chances as a recurrence of inco-ordinate uterine action is uncommon.

It would appear reasonable that with the provisos enumerated in this paper, to continue to try and attain vaginal delivery whenever possible in ladies previously delivered by Caesarean section.

\section{REFERENCES}

Case, Babara D., Corcoran, R., Jeffcoate, N. and Randle, G. H. (1971). J. Obstet. Gýnaec. Brit. Emp. 78, 203.

Department of Health and Social Security (1969). Report on Confidential Enquiries into Maternal Deaths (1964-1966) H.M.S.O. London.

McGarRY, J. A. (1969). J. Obstet. Gynaec. Brit. Emp. 76, 137.

Riva, H. L. and TeICH, J. C. (1961). Amer J. Obstet. Gynaec. 81, 501.

Second Report of the 1958 British Perinatal Mortality Survey, The (1969). Perinatal Problems. E. \& S. Livingstone Ltd. Edinburgh. 